\title{
Recreation, Sport and an Aging Population
}

\author{
By Steven Carney ${ }^{*} \&$ Hal Walker ${ }^{*}$
}

\begin{abstract}
America is getting older. The first of the Baby Boom Generation (those born from 1945 to 1964) - 76 million strong - reached the age of retirement in 2011. This mass of people, combined with longer lives and lower birth rates, is changing the demographics of the United States and impacting our society. Between now and 2029, the population over age 65 will increase from $13 \%$ of the population to 20\%, growing at a rate 7 times faster than the rest of the population. This will not be a temporary shift. Long range estimates are for the percentage of the total population over the age of 65 to remain above $20 \%$ for the next 50 years. Dire forecasts are already being heard for the long-term sustainability of Social Security and Medicare and the impact on economic growth and businesses from the retirement of skilled workers. Beyond the workplace and healthcare, this shift will require sport organizations - both recreational and professional - to adjust in order to meet the needs and desires of this formidable market.
\end{abstract}

Keywords: Sport, Recreation, Aging, Fans, Participation

\section{Introduction}

Every day 10,000 baby boomers retire. That will be true for another 19 years. Those who are 50 and older significantly out-earn those who are younger, and have overwhelmingly more accumulated spendable wealth beyond income than their younger counterparts. As they continue to age, they will also have increasingly more time to spend on sports interests - interests they say will never die. (Luker, 2012, para. 13).

This quote, from a survey of age and fan interest in sport, points to the need for sport organizations to focus on their key customers and the changing demographics in the United States. Too often these organizations try to appeal to the 18 to 35 demographic and neglect older populations. As Luker (2012) has noted above, both recreational and professional sport organizations cannot ignore the needs of older consumers. Important for understanding this segment is the continuing aging of America, as well as research related to age and sport participants and spectators.

*Assistant Professor of Sport Business, Saint Leo University, USA.

${ }^{\dagger}$ Associate Professor of Sport Management, Elon University, USA. 


\section{Review of Literature}

\section{The Aging of America}

The United States has over 320 million citizens (Colby and Ortman 2014). As the population has increased, there has also been an increase in the number of people over the age of 65 . But we are not just seeing an increase in the size of the population over 65 , the percentage of the population over age 65 is also increasing. In 2000, individuals over the age of 65 measured 35 million - about $11 \%$ of the total. In 2005, that number increased to 36.6 million and 12\%. In 2015 the number of Americans over the age of 65 was 47.8 million, and made up almost $15 \%$ of the total (see Figure 1).

Much of this increase is attributed to the Baby Boom generation; a 20-year increase in the population between 1945 and 1964. The size of the US Baby Boom generation reached 72.5 million in 1964, and increased to 78.8 million by 1999 (because of immigration to the US). As this generation has aged, structures in the US have had to adjust to the demand for services; elementary schools, high schools, colleges, the workforce, and now retirement. Boomers began to turn 65 in 2010, and the tail end of this generation will not turn 65 until 2029. The size of the US population over the age of 65 in 2030 is projected to be 73 million, and will comprise $20.3 \%$ of the total population (Colby and Ortman 2014).

These changes in age distribution caused by the Baby Boom generation are not a short-term adjustment to the demographics of the United States. Long-term projections of the US population show the changes taking place in the percentage of the population will be permanent, and the percentage of the population over the age of 65 will remain above $20 \%$ for the foreseeable future. Some projections estimate the percentage of the population over the age of 65 may reach $25 \%$ by 2060 (Colby and Ortman 2014).

Figure 1. Number of Persons 65+, 1990 to 2060 (numbers in millions)

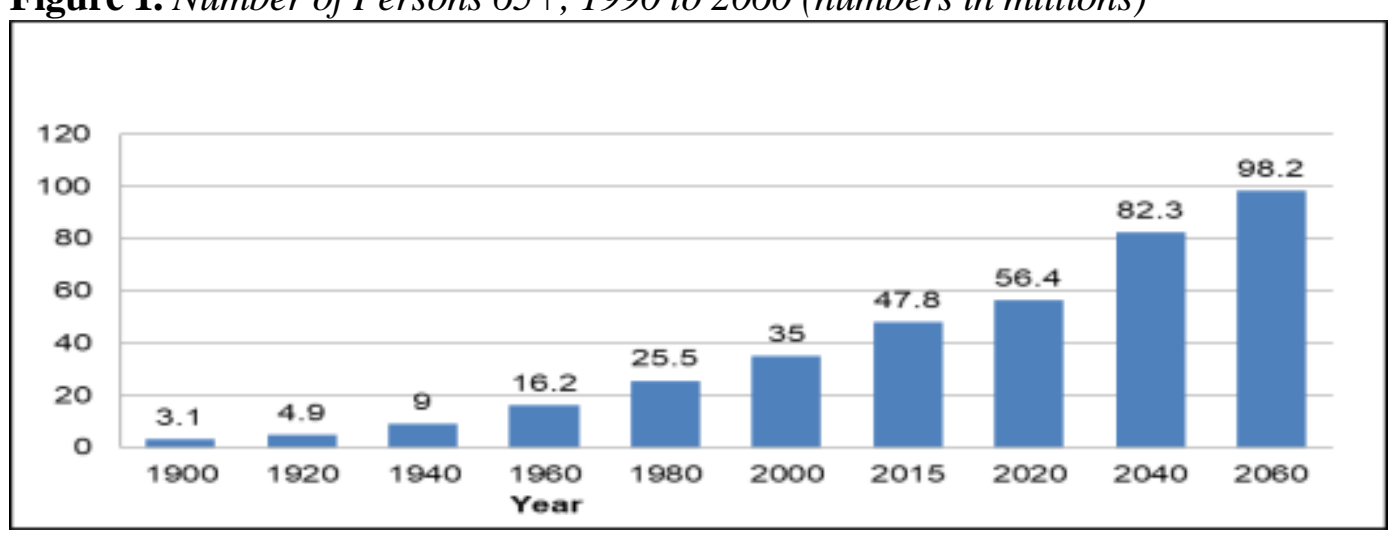

Source: Colby and Ortman (2014).

As the population has aged, Americans have continued to lead active lives. Many people take advantage of the time available in retirement to volunteer, travel, or pursue educational opportunities, entertainment options or recreational activities (Czaja and Sharit 2009). With the long-term projections in the size of the 
population over the age of 65, services for older Americans will need to adjust to the increased demand and the limitations of older consumers. For instance, research shows that $35 \%$ of people over the age of 65 have some level of disability, including $23 \%$ with ambulatory difficulty, $15 \%$ with hearing difficulty, and $9 \%$ with vision difficulty (see Figure 2). Recreational sport and professional sport organizations should understand the needs of this market segment.

\section{Recreational Sport Participation and an Aging Population}

Even if an individual does not suffer from a disability, there are notable declines that impact performance; in visual and auditory acuity, in reaction times, in motor skills and agility, and in focus (Czaja and Sharit 2009). While these may limit the ability of an older athlete to compete against athletes in their prime, Masters-level competitions allow competitive athletes to compete against each other in defined age brackets. Some road races include age-graded competitions, which compares athlete times to top performances in their age group. With improvements in training, nutrition and recovery, competitive athletes have been able to maintain high-level conditioning longer than previously thought possible. Meb Keflezighi won the 2014 Boston Marathon at 38 years of age against worldclass athletes 10 to 20 years his junior. In 2004, 73 year-old Ed Whitlock ran 2:54:48 for a marathon; an age-graded performance that would equal an athlete in his prime running 2:04:48. At 81, Whitlock's VO2 Max was measured at 54, which is a good score for a college student (Longman 2016). While some of these performances can be attributed to improvements in training, Pollock et al. (1987) found that Masters track athletes that maintained their training showed no significant changes in aerobic capacity over a 10 -year period.

Figure 2. Percentage of Persons $65+$ with a Disability

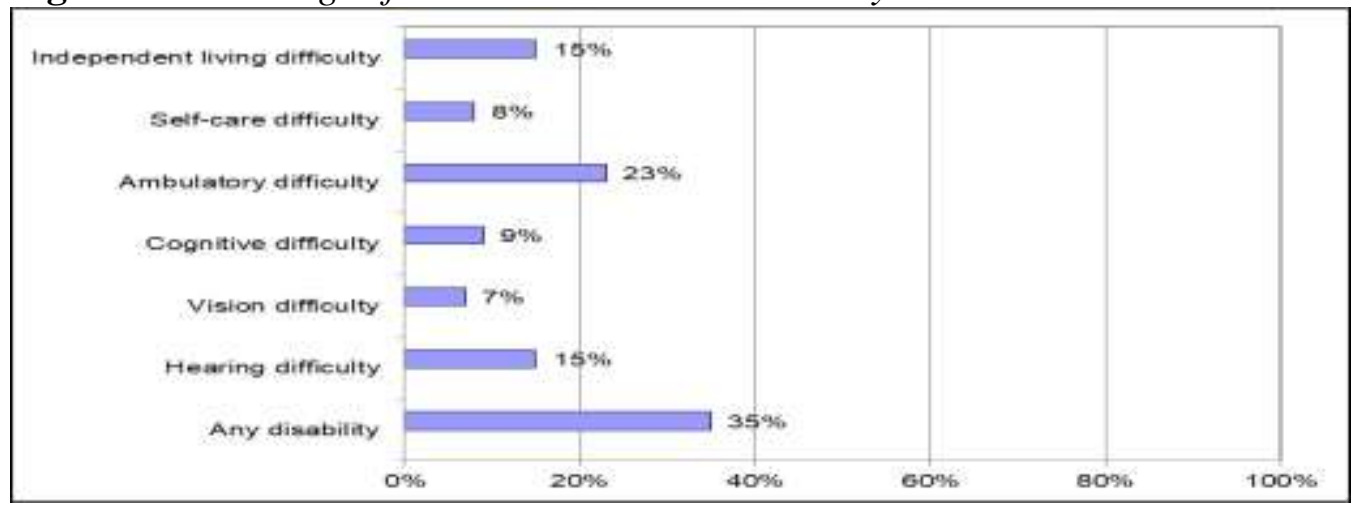

Source: U.S. Census Bureau (2015).

Not everyone remains competitive as they age, and it is hard to maintain highlevel training. The good news is that, even for people that participate in recreational sports and activities, there are positive benefits gained from engaging in regular physical activity. These benefits include; 1) higher high-density lipoprotein (HDL) cholesterol levels (the "good" cholesterol), 2) improved weight control, 3) increased bone density, 4) increased muscle mass, and 5) greater 
feelings of psychological well-being (Baker et al. 2009). Physical activity also helps to fight the onset of diseases that were previously thought to be related to aging - such as diabetes, high blood pressure and colon cancer. Other symptoms of aging, like the loss of bone density and muscle mass, are now seen as the result of physical inactivity, not aging (Atkinson 2009). The message of these benefits of physical activity is getting out, too. Ory et al. (2003) found that $98 \%$ of adults over the age of 50 recognized the importance of physical activity. Unfortunately, knowledge has not led to action.

Even though most adults know that physical activity has many positive benefits, $41 \%$ of individuals between the ages of 50 and 65 are inactive, and $52.6 \%$ over the age of 65 engage in no aerobic or strength-training activities (Kruger et al. 2007). The Healthy People 2010 report, developed by the U.S. Department of Health and Human Services, established recommendations for regular aerobic and strength-training activities. Regular aerobic activity was defined as either 1) light- to moderate-intensity activity for at least 30 minutes per day on at least 5 days per week, or 2) vigorous-intensity activity for at least 20 minutes per day on at least 3 days per week. Regular strength-training activity was defined as engaging in muscular strength or endurance activities on 2 or more days per week. Of the respondents, $26.1 \%$ participated in regular aerobic training, $13.7 \%$ participated in regular strength training, and only $8.2 \%$ participated in both the recommended aerobic and strength-training activities.

These results seem to conflict with results of the Physical Activity Council's 2017 Participation Report (though it does use different categories). First of all, participation rates were segmented by generations, from the Baby Boomers to Generation Z, instead of age. Next, five categories of activities were developed; 1) Inactive, 2) Low/Medium Calorie activities, 3) Casual \& Low/Medium Calorie activities, 4) Active \& High Calorie, and 5) Active to a Healthy Level (see Table 1). Each category was linked to specific activities. Since all Baby Boomers are older than 50, then the difference between the inactive populations in these studies is almost $20 \%$. This difference is further complicated by the fact that the Inactive category in the 2017 Participation Report included not only adults who engaged in no leisure activities, but also walking, birdwatching, fishing and other low calorie activities.

Table 1. Participation Rates Segmented by Generation

\begin{tabular}{|c|c|c|c|c|c|}
\hline & Inactive & $\begin{array}{c}\text { Low/Med } \\
\text { Calorie }\end{array}$ & $\begin{array}{c}\text { Casual \& } \\
\text { Low/Med } \\
\text { Calorie }\end{array}$ & $\begin{array}{c}\text { Active \& } \\
\text { High Calorie }\end{array}$ & $\begin{array}{c}\text { Active to a } \\
\text { Healthy } \\
\text { Level }\end{array}$ \\
\hline $\begin{array}{c}\text { Gen Z } \\
(2000+)\end{array}$ & $17.6 \%$ & $13.8 \%$ & $20.6 \%$ & $19.4 \%$ & $28.6 \%$ \\
\hline $\begin{array}{c}\text { Millennials } \\
(1980-1999)\end{array}$ & $24.6 \%$ & $15.0 \%$ & $13.5 \%$ & $10.7 \%$ & $36.4 \%$ \\
\hline $\begin{array}{c}\text { Gen X } \\
(1965-1979)\end{array}$ & $27.2 \%$ & $18.4 \%$ & $8.0 \%$ & $9.6 \%$ & $36.8 \%$ \\
\hline $\begin{array}{c}\text { Boomers } \\
(1945-1964)\end{array}$ & $33.7 \%$ & $27.8 \%$ & $4.8 \%$ & $6.1 \%$ & $27.6 \%$ \\
\hline
\end{tabular}

Source: Physical Activity Council Report (2017) 
Low/Med Calorie activities were defined as stretching, walking for fitness, bowling and table tennis. Casual \& Low/Med Calorie activities included yoga, free weights, Tai Chi, and golf. Casual participants identified they were active 1 to 50 times a year. Active and High Calorie activities included high intensity training, cardio kickboxing, spinning and other fitness classes, and participants indicated they were active 51 to 150 times a year. Active to a Healthy Level sports were activities that were aerobic in nature, like running and swimming, but also included competitive sports. Individuals participated in these activities more than 150 times in a year.

In this study, inactive and low/medium calorie activities increased as individuals aged, and casual and active $\&$ high calorie activities decreased. This could be because the inactive and low calorie activities included such lifetime activities as birdwatching, walking and golf. The medium to high activities may differ because of the high impact sports and classes in those categories. Finally, while the active to a healthy level activities did include some competitive and team sports, it also included some lifetime activities like running, swimming and tennis.

It is important to note that even light exercise is beneficial. Lorpinzi et al. (2015) found that adults $65+$ that engaged in light levels of activity (300 minutes a week) resulted in lower BMI scores, waist circumference and insulin resistance. They also had less of a risk of chronic diseases. This study confirms the belief that it is better to do something than nothing, but it should be noted here that the cutoff used in this study to gain benefits was 60 minutes a day, 5 days a week.

The 2017 Participation Report also included a more traditional breakdown of sport activities by generation. In most of the sport categories, participation decreased as age increased (see Table 2). The one category where the Boomers $(50+)$ generation was active at a higher level than Gen $\mathrm{Z}$ was Fitness Sports. This seems reasonable, as older Americans emphasize maintaining fitness, while Gen Z respondents also indicated high levels of participation in Individual Sports (48.2\%), Team Sports (58.8\%) Outdoor Sports (61.8\%) and Fitness Sports $(50.8 \%)$ - which would mean they are participating in more than one activity.

Table 2. Activity Category Segmented by Generation

\begin{tabular}{|l|c|c|c|c|c|c|c|}
\hline & $\begin{array}{c}\text { Individual } \\
\text { Sports }\end{array}$ & $\begin{array}{c}\text { Racquet } \\
\text { Sports }\end{array}$ & $\begin{array}{c}\text { Team } \\
\text { Sports }\end{array}$ & $\begin{array}{c}\text { Outdoor } \\
\text { Sports }\end{array}$ & $\begin{array}{c}\text { Winter } \\
\text { Sports }\end{array}$ & $\begin{array}{c}\text { Water } \\
\text { Sports }\end{array}$ & $\begin{array}{c}\text { Fitness } \\
\text { Sports }\end{array}$ \\
\hline $\begin{array}{l}\text { Gen Z } \\
(2000+)\end{array}$ & $48.2 \%$ & $18.8 \%$ & $58.8 \%$ & $61.8 \%$ & $13.1 \%$ & $17.5 \%$ & $50.6 \%$ \\
\hline $\begin{array}{l}\text { Millennials } \\
(1980-99)\end{array}$ & $43.6 \%$ & $20.2 \%$ & $31.8 \%$ & $57.4 \%$ & $12.2 \%$ & $20.3 \%$ & $66.7 \%$ \\
\hline $\begin{array}{l}\text { Gen X } \\
(1965-79)\end{array}$ & $36.9 \%$ & $13.4 \%$ & $17.9 \%$ & $51.4 \%$ & $7.0 \%$ & $14.8 \%$ & $66.2 \%$ \\
\hline $\begin{array}{l}\text { Boomers } \\
(1945-64)\end{array}$ & $24.1 \%$ & $7.1 \%$ & $6.4 \%$ & $38.6 \%$ & $2.9 \%$ & $9.2 \%$ & $60.0 \%$ \\
\hline
\end{tabular}

Source: Physical Activity Council Report (2017).

Most of the research on participation in sport shows a decrease in participation as we age. Does this decrease in participation result from limitations as a result of aging, or from a lack of interest in sport? Atkinson (2009) noted that 
athletic participation is only one way to engage in sport. We can also participate in sport as spectators and fans. In discussing this decrease in participation in baseball, Krizek (2002) stated that "as I grew older and curtailed my active participation in baseball, my relationship with the game as a fan changed" (p. 404). Next we will consider research related to age and sport fans and spectators.

\section{Sport Spectatorship and an Aging Population}

If fans do reduce active participation in sports and increase participation as fans and spectators, we should see some indication of this in studies of sports fans and age. The Gallup Sports Poll has tracked the percentage of the population that identify themselves as sports fans since the year 2000. Results have ranged from $57 \%$ to $66 \%$, but have generally been consistently between $59 \%$ and $61 \%$. These results can also be tracked by age group. In the 2015 poll, the percentage of people that identified themselves as sports fans decreased from just above $60 \%$ in the 18 29 and $20-49$ age groups, to $55 \%$ for the 50-65 age group and 57\% for the $65+$ age group (Jones 2015). While these statistics seem to show a decrease in the percentage of sport fans as people age, studies of fan age related to specific sports seem to differ.

First, Gillies (2015) found a difference between the average age of fans of the NBA (37), NFL (47) and MLB (53). If you look at the age and percentage of league fans, you can see the difference (see Table 3). While baseball has the greatest percentage of fans $50+$, the percentage of younger fans is very similar to other sports. The $28 \%$ of fans between the ages of 18 and 34 is not far behind NASCAR $(29.4 \%)$ or the NHL (29.6\%), and once fans enter the 35 to 49 age group the percentage is in line with other sports. The exception here is Major League Soccer (MLS), which has a greater percentage of fans in the 18 to 34 age group than the other two age groups.

Table 3. Age and Percentage of League Fans

\begin{tabular}{|l|c|c|c|c|c|c|}
\hline & MLB & MLS & NASCAR & NFL & NHL & NBA \\
\hline Age 18-34 & $28.0 \%$ & $37.8 \%$ & $29.4 \%$ & $31.9 \%$ & $29.6 \%$ & $33.4 \%$ \\
\hline Age 35-49 & $28.8 \%$ & $31.8 \%$ & $30.0 \%$ & $28.9 \%$ & $29.1 \%$ & $32.1 \%$ \\
\hline Age 50+ & $43.1 \%$ & $30.4 \%$ & $40.6 \%$ & $39.2 \%$ & $41.3 \%$ & $34.4 \%$ \\
\hline
\end{tabular}

Source: Fan demographics among North American sport leagues (2010).

What makes baseball more attractive to older adults? In a study of baseball fans older than 60, Krizek (2002) found six reasons for the appeal of baseball to older fans; 1) the imperfect nature of baseball, 2) the connectedness of fandom, 3) baseball as a social outlet, 4) the slower pace of the game, 5) the difference between fan and spectator, and 6) the aural (vs. visual) experience. Some of these themes that attract older fans may differ from other sports, but the study of cohorts of fans as they age may provide sport marketers with information necessary to appeal to these fans.

Luker (2012) has examined the impact of sports fans 50 and older and has identified several reasons for sport organizations to take a closer look at this demographic. One of the most telling answers was when he asked this question: 
"As you get older, do you think your enjoyment of sports will increase or decrease?" For all age groups, at least 59\% said that their interest would stay the same or increase, and 33\% of respondents over the age of 65 said they expected their interest in sports to increase.

Another justification for developing a strategy for older fans is that it is easier to keep current customers than attract new ones. Gibson et al. (2002) examined long-term fans of the Florida Gators to find characteristics that set Gators apart from Gator fans. The authors found that four of the six characteristics of serious leisure related to life stages; 1) long-term career, 2) significant personal effort, 3) durable self-benefits, and 4) identification. Long-term career was identified as the impact of different life events on fandom; e.g. getting married, having children, and aging. As their life changed, so did their fan behaviours. Significant personal effort relates to the cost of being a lifelong fan; not just money, but the time and commitment necessary. Durable self-benefits included family time, social interactions and friendships that were enhanced through shared experiences, and identification included apparel, merchandise and activities that established their identity as a fan of the Gators. The generational and life stage aspects of sport participants and fans provide some important lessons for these organizations and opportunities for additional study.

\section{Recommendations for Future Research}

Recreation and sport organizations need to realize that the population in the United States $65+$ is increasing faster than any other segment. There will be a need to make accommodations for this growing segment, in particular with regard to the growing number of individuals with disabilities. If $35 \%$ of adults over the age of 65 have a physical limitation (ambulatory, visual or hearing) (Czaja and Sharit 2009), there will be a greater demand for accommodations for those disabilities in recreation and sport programs. Do these organizations have a plan for meeting the needs of these individuals?

\section{Recreational Sport Participation and Age}

One of the most important statistics from this research is that $98 \%$ of adults $50+$ know they need to participate in some type of physical activity (Ory et al. 2003). Do individuals who are inactive know the recommended levels of aerobic, strength-training and flexibility? Do active individuals know the recommended levels of aerobic, strength-training and flexibility? Are they aware of the benefits of light fitness activities? What will motivate individuals $50+$ and $65+$ to begin a fitness and wellness program? What will motivate them to continue those activities?

If $60 \%$ of adults $65+$ participate in Fitness Sports, $38 \%$ participate in Outdoor Sports, and 24\% participate in Individual Sports (PAC Participation Report 2017), do the recreational sport programs offered match the current participation rates and population percentage of adults $65+$ ? Recreational sport organizations should 
develop a holistic strategy that incorporates participants in different age cohorts (Generation Z, Millennials, Gen X, Baby Boomers).

\section{Sport Spectatorship and Age}

While sport organizations identify methods to increase the percentage of fans in the 18-34 age group, they should also emphasize the satisfaction of current fans 50+, with the time, interest and disposable income to (Luker 2012). Have sport organizations developed a holistic strategy that incorporates fans in different age cohorts (Generation Z, Gen X, Millennials, Baby Boomers) at different stages of their life? Is there a method to examine how each cohort moves through life stages and meet their needs at each stage?

New research should identify the needs of fans at different life stages. If $35 \%$ of people over the age of 65 have some level of disability (U.S. Census Bureau 2015), and the number of individuals over the age of 65 is increasing at a greater percentage than the rest of the population, then sport organizations will need to provide greater accommodations for their older fans. Have sport organizations measured the number of fans with physical limitations? Do they have a plan to meet the needs of the increasing percentage of adults $65+$ ?

\section{Combined Recreational Sport Participation and Sport Spectatorship}

If engaging sport fans throughout their lifespan is important for sport organizations, there should also be an investigation of the relationship between the decrease in sport participation as individuals age (PAC Participation Report 2017) and the increase in sport fans (Fan demographics among 2010). While there has been research to investigate the interest in sports, there is no research to examine continuing interest in recreational sport or physical activity.

\section{Conclusions}

Age has been a variable in the study of physical activity, recreational sport participation and sport spectatorship. Much of the research has examined differences in age groups, changes related to aging, and characteristics of generational cohorts. While there has been much research that examined physical and recreational activity, there is an opportunity to apply these results to recreational and sport organization.

Recreation programs should continue to promote the benefits of low levels of activity. Kruger et al. (2007) only considered benefits of meeting Healthy People 2010 recommendations. The 2017 Participation Report included low calorie activities (walking, bird watching and fishing) in the Inactive category. Lorpinzi et al. (2015) found that adults 65+ that engaged in light levels of activity (300 minutes a week) resulted in lower BMI scores, waist circumference and insulin resistance. They also had less of a risk of chronic diseases. Develop recreational programs to meet the needs of each of these groups at their current level of fitness, 
with the goal of working towards the recommended levels of fitness in Healthy People 2010.

Recreational sport organizations should develop life stage recreational programs. If $60 \%$ of adults $65+$ participate in Fitness Sports, $38 \%$ participate in Outdoor Sports, and 24\% participate in Individual Sports (PAC Participation Report 2017), program offerings should reflect these levels. Organizations should also consider accommodations for individuals with disabilities, and be aware of generational differences that may impact participation.

Some sports have identified aging of fans as an issue, but there seems to be more concern and adjustments that cater to younger fans (Gillies 2015). According to McHugh et al. (2016), there is an analysis of the trends of Generation Y/Millennials (born 1985-2000) and Generation Z (born after 2000), and even the globalization of sport, but there was no mention of the aging population and considerations of this fan segment.

"The world is aging; as athletes, we are aging; as fans and spectators, we are aging" (Atkinson 2009: 18). As the size and percentage of the population over the age of 65 increases, recreation and sport organizations need to adjust their services, communication channels, and marketing methods to meet the needs of this segment.

\section{References}

Atkinson JL (2009) Age Matters in Sport Communication. The Electronic Journal of Communication 19: $3 \& 4$.

Baker J, Fraser-Thomas J, Dionigi RA, Horton S (2009) Sport Participation and Positive Development in Older Persons. Eur Rev Aging Phys Act 7(1): 3-12. DOI= 10.1007/ s11556-009-0054-9.

Colby SL, Ortman JM (2014) The Baby Boom Cohort in the United States: 2012 - 2060. United States Census Bureau. (May, 2014). Available at https://www.census.gov/ prod/2014pubs/p25-1141.pdf

Czaja AJ, Sharit J (2009) The Aging of the Population: Opportunities and Challenges for Human Factors Engineering. The Bridge 39(1): 34-40.

Fan Demographics among North American Sport Leagues (2010) SportBusiness Daily. (June 9).

Gibson H, Willming C, Holdnak A (2002) "We're Gators...not just Gator fans": Serious leisure and University of Florida football. Journal of Leisure Research 34(4): 397425.

Gillies T (2015) Baseball Thrives, but struggles to overcome its age. CNBC. (July 12, 2015).

Jones JM (2015) As Industry Grows, Percentage of U.S. Sports Fans Steady. Gallup Marketplace. (June 17, 2015). Available at http://www.gallup.com/poll/183689/ industry-grows-percentage-sports-fans- steady.aspx.

Krizek B (2002) The grayer side of the game: Baseball and the "older" fan. In G Gumpert and J Drucker (eds) Take Me Out to the Ballgame: Communicating Baseball, 401428. Cresskill, New Jersey: Hamptong Press.

Kruger J, Carlson SA, Buchner D (2007) How active are older Americans? Prev Chronic Dis [serial online]. 4, 3 (July, 2007). Available at http://www.cdc.gov/pcd/issues 
/2007/jul/06_0094.htm.

Longman J (2016) 85 Year-old is so Fast that even Scientists Marvel. New York Times. (Dec. 28, 2016).

Loprinzi PD, Lee H, Cardinal BJ (2015) Evidence to Support Including Lifestyle Lightintensity Recommendations in Physical Activity Guidelines for Older Adults. American Journal of Health Promotion 29(5): 277-284.

Luker, R (2012) Why Sports Industry must Recognize Importance of Older Fans. Street \& Smith's Sports Business Journal. (June 25, 2012).

McHugh J, Bronson P, Watters E (eds) (2016) The Future of Sports. Delaware North. Available at http://futureof.org/wp-content/uploads/The-Future-of-Sports-2016-Re port.pdf.

Ortman JM, Velkoff VA, Hogan H (2014) An Aging Nation: The Older Population in the United States, 25-1140. U.S. Census Bureau, Washington, DC. (May, 2014). Available at https://www.census.gov/prod/2014pubs/p25-1140.pdf.

Ory M, Hoffman M, Hawkins M, Sanner B, Mockenhaupt R (2003) Challenging Aging Stereotypes: Strategies for Creating a more Active Society. American Journal of Preventive Medicine. 25(3): 164-171.

Physical Activity Council (2017) Physical Activity Council Participation Report. (March 1, 2017). Available at http://www.physicalactivitycouncil.com/pdfs/current.pdf.

Pollock ML, Foster C, Knapp D, Rod JL, Schmidt DH (1987) Effect of Age and Training on Aerobic Capacity and Body Composition of Master Athletes. Journal of Applied Physiology 62(2): 725-731.

Reznik GL, Shoffner D, Weaver DA (2005/2006) Coping with the Demographic Challenge: Fewer Children and Living Longer. Social Security Bulletin 66(4): 37-45. Available at https://www.ssa.gov/policy/docs/ssb/v66n4/v66n4p37.html.

U.S. Census Bureau (2015) American Community Survey. Available at https://www.cen sus.gov/programs-surveys/acs/technical-documentation/summary-file-documentati on.2015.html.

U.S. Department of Health and Human Services (2010) Healthy People 2010: Understanding and Improving Health. $2^{\text {nd }}$ ed. Washington, DC: U.S. Government Printing Office, (Nov. 2000). Available at http://wonder.cdc.gov/data2010/focus.htm. 